\title{
Reduction of ultraviolet light-induced DNA damage in human colon cancer cells treated with a lactoferrin-derived peptide
}

\author{
C. Freiburghaus, ${ }^{*}$ H. Lindmark-Månsson, $†$ M. Paulsson, ${ }^{*}$ and S. Oredsson ${ }^{1}$ \\ *Department of Food Technology, Engineering and Nutrition, Lund University, PO Box 124, 22100 Lund, Sweden \\ †Swedish Dairy Association, Scheelevägen 17, 22370 Lund, Sweden \\ ‡Department of Biology, Lund University, Sölvegatan 35, 22362 Lund, Sweden
}

\section{ABSTRACT}

Treatment of Caco-2 cells with the peptide lactoferri$\operatorname{cin}_{4-14}$, results in reduction of the growth rate by prolongation of the $\mathrm{S}$ phase of the cell cycle. Lactoferricin $n_{1-25}$ is formed in the gut by cleavage from lactoferrin and the bioactive amino acids are found within lactoferricin ${ }_{4-14}$. Our hypothesis is that the reduction of the rate of $\mathrm{S}$ phase progression may result in increased DNA repair. To test this hypothesis, Caco-2 cells were subjected to UV light that caused DNA lesions and then the cells were grown in the absence or presence of $2.0 \mu \mathrm{M}$ lactoferricin ${ }_{4-14}$. Evaluation of DNA strand breaks using the comet assay showed that lactoferricin ${ }_{4-14}$ treatment indeed resulted in a reduction of comets showing damaged DNA. In the search for a mechanism, we have investigated the levels of several proteins involved in cell cycle regulation, DNA replication, and apoptosis using Western blot. Lactoferricin ${ }_{4-14}$ treatment resulted in an increased expression of flap endonuclease-1 pointing to increased DNA synthesis activity. Lactoferricin ${ }_{4-14}$ treatment decreased the expression of the proapoptotic protein B-cell lymphoma 2-associated X protein (or Bax), indicating decreased cell death. As we have found previously, lactoferricin ${ }_{4-14}$ treatment reduced the expression of cyclin $\mathrm{E}$ involved in the $\mathrm{G}_{1} / \mathrm{S}$ transition. Immunofluorescence microscopy showed that a lower $\gamma$-H2AX expression in lactoferricin ${ }_{4-14}$-treated cells, pointing to more efficient DNA repair. Thus, altogether our data show that lactoferricin ${ }_{4-14}$ treatment has beneficial effects.

Key words: DNA strand break, DNA repair, comet assay, lactoferricin ${ }_{4-14}$

\section{INTRODUCTION}

Among the most common forms of cancer is colorectal cancer, cancer of the colon and rectum, which is responsible for the worldwide death of 655,000 people

Received December 20, 2011.

Accepted May 20, 2012.

${ }^{1}$ Corresponding author: stina.oredsson@biol.lu.se every year (World Cancer Research Fund/American Institute for Cancer Research, 2007). Colorectal cancer commonly starts as a benign polyp, which over time may develop into a malignant tumor (Lynch and de la Chapelle, 2003). Diet, smoking, and physical inactivity are factors that may enhance the risk of colorectal cancer (World Cancer Research Fund/American Institute for Cancer Research, 2007). Of all cases of colorectal cancer, $95 \%$ occur randomly, whereas only $5 \%$ are due to genetic predisposition (Lynch and de la Chapelle, 2003).

Milk consumption has in several studies been linked to improved health, with decreased risks of diabetes and metabolic syndrome as well as colon cancer (World Cancer Research Fund/American Institute for Cancer Research, 2007; Elwood et al., 2008). Calcium in milk is an acknowledged factor for the colon cancer preventive effects (Ahmed, 2004; Cho et al., 2004), but other components have an effect as well. Lactoferrin is a well-characterized bioactive milk protein with reported health beneficial effects (Damiens et al., 1999; Berkhout et al., 2002; van Belzen, 2002; Min and Krochta, 2005). Most of the documented effects of lactoferrin are antibacterial (Arnold et al., 1980; Ellison and Giehl, 1991), but antitumor effects have been reported both in vivo and in vitro (Arnold et al., 1980; Yoo et al., 1997; Min and Krochta, 2005). During digestion, the bioactive peptide lactoferricin (Lfcin) is released from this $80-\mathrm{kDa}$ iron binding whey protein (Bellamy et al., 1992). Lactoferricin and smaller peptides containing the bioactive amino acids of Lfcin (e.g., Lfcin $_{4-14}$ ) have anticancer, antibacterial, and antiparasitic activities (Wakabayashi et al., 2003; Mader et al., 2007; Eliassen et al., 2006; León-Sicairos et al., 2006).

We have previously shown that Lfcin $_{4-14}$ prolongs the $\mathrm{S}$ phase of the cell cycle in the human colon cancer cell line Caco-2, thereby significantly reducing the growth rate over time (Freiburghaus et al., 2009). This observation may have several implications for human health. First, it may result in a reduced cell proliferation rate of a cancer population. It may also imply that normal colon cells grow slightly slower, reducing the number of population doubling times during a lifetime enough to 
prevent cancer development but not impairing normal function. We are investigating the effect of $\operatorname{Lfcin}_{4-14}$ on normal human colon cells in a separate investigation. However, we decided to use Caco-2 cells for the initial investigating of our hypothesis that $\mathrm{Lfcin}_{4-14}$ treatment may affect DNA repair through the prolongation of the $\mathrm{S}$ phase, keeping in mind that they are cancer cells.

In this study, we have used UV light-induced DNA damage as a model to cause DNA lesions and then DNA repair was investigated using the comet assay (Fairbairn et al., 1995). Thus, Caco-2 cells were exposed to UV light and were then grown in the absence or presence of $2.0 \mu \mathrm{M} \mathrm{Lfcin} \mathrm{Lf}_{4-14}$, a concentration that significantly prolonged the cell cycle (Freiburghaus et al., 2009). In the alkaline comet assay, both single- and double-strand DNA breaks are detected in individual cells (Fairbairn et al., 1995). The present work indicates that cells treated with Lfcin $_{4-14}$ had less DNA damage compared with untreated control cells.

Histones are proteins found in the nucleus and they are involved in DNA packaging into structural units called nucleosomes (Zlatanova et al., 2009). Four major core histone protein families exist in mammalian cells, namely $\mathrm{H} 2 \mathrm{~A}, \mathrm{H} 2 \mathrm{~B}, \mathrm{H} 3$, and $\mathrm{H} 4$. The histone $\mathrm{H} 2 \mathrm{AX}$ belongs to the histone $\mathrm{H} 2 \mathrm{~A}$ family. As a reaction to DNA double-strand breaks, H2AX becomes phosphorylated on serine 139, and is then called $\gamma$-H2AX (Foster and Downs, 2005). This phosphorylated form, together with a mediator complex consisting of several small proteins, acts as a signal amplifier for downstream actions for DNA repair (Reinhardt and Yaffe, 2009). The phosphorylation, which is dependent on dose and time, occurs within minutes after exposure to UV light or $\gamma$-radiation. Thus, $\gamma-\mathrm{H} 2 \mathrm{AX}$ is a sensitive target for detecting double-strand breaks. Using immunofluorescence with a primary antibody directed exclusively against H2AX phosphorylated at serine 139, $\gamma$-H2AX can be visualized as small spots in the nucleus. In the present work, we show that $\operatorname{Lfcin}_{4-14}$ treatment of UV light-treated Caco-2 cells reduced the amount of $\gamma$-H2AX. Western blot was also used to study the expression of several other proteins involved in cell cycle progression, DNA repair, and apoptosis and we observed changes in expression that can be interpreted to support our hypothesis that $\mathrm{Lfcin}_{4-14}$ treatment resulted in increased DNA repair.

\section{MATERIALS AND METHODS}

\section{Lactoferricin}

Bovine Lfcin $_{4-14}$ (L1290, 126K1550; Sigma-Aldrich Co., St Louis, MO) was dissolved in PBS (8 $\mathrm{g}$ of $\mathrm{NaCl} / \mathrm{L}, 0.2 \mathrm{~g}$ of $\mathrm{KCl} / \mathrm{L}, 1.15 \mathrm{~g}$ of $\mathrm{Na}_{2} \mathrm{HPO}_{4} / \mathrm{L}$, and
$0.2 \mathrm{~g}$ of $\left.\mathrm{KH}_{2} \mathrm{PO}_{4} / \mathrm{L}, \mathrm{pH} 7.3\right)$ to give a $100 \mu M$ stock solution, which was sterile filtered $(0.2-\mu \mathrm{m}$ pore size) before addition to the cell cultures. Aliquots of the stock solution were kept at $-20^{\circ} \mathrm{C}$ until use. Lactoferri$\operatorname{cin}_{4-14}$ is supposed to contain the bioactive amino acids of Lfcin $_{1-25}$ (Bellamy et al., 1992; Vogel et al., 2002; Jing et al., 2006). The $\operatorname{Lfcin}_{4-14}$ dose was chosen based on calculation of a daily intake of $2 \mathrm{~L}$ of milk (Troost et al., 2001; Freiburghaus et al., 2009).

\section{Cell Culture}

The Caco-2 cell line was purchased from American Type Culture Collection (Manassas, VA; HTB-37). Growth medium components were purchased from Biochrom AG (Berlin, Germany) and tissue culture plastics from Nunc A/S (Roskilde, Denmark). Cells were grown in RPMI1640 medium supplemented with penicillin $(100 \mathrm{U} / \mathrm{mL})$, streptomycin $(100 \mu \mathrm{g} / \mathrm{mL})$, nonessential amino acids $(1 \mathrm{~m} M)$ and $10 \%$ (vol/vol) fetal calf serum throughout this study. All experiments with Caco- 2 cells were performed within passages 8 to 40. The cells were passaged twice per week and never allowed to reach confluence. Cultures were grown in a humidified atmosphere of $95 \%$ air and $5 \% \mathrm{CO}_{2}$ at $37^{\circ} \mathrm{C}$. These conditions were kept unchanged throughout the study. For all experiments, several replicate cultures, consisting of $0.5 \times 10^{6}$ plateau phase cells seeded into $5 \mathrm{~mL}$ of medium in Petri dishes (5-cm diameter) were set up.

\section{Treatment with Lfcin $_{4-14}$}

Twenty-four hours after seeding, the growth medium was supplemented with $2.0 \mu M \mathrm{Lfcin}_{4-14}$ or PBS of an equal volume as the volume of $\operatorname{Lfcin}_{4-14}$ that was added (control). In some experiments defined below, totally unexposed cells were included (defined as unexposed). Cells were harvested by trypsinization after 24,48 , or $72 \mathrm{~h}$ of $\mathrm{Lfcin}_{4-14}$ treatment.

\section{Induction of DNA Damage by UV Light}

Twenty-four hours after seeding, the growth medium was removed and the cells were exposed to UV light $\left(3.18 \pm 0.2 \mathrm{~mW} / \mathrm{cm}^{2}\right)$ for $2 \mathrm{~min}$ to induce DNA damage. Different UV light exposure times were tested initially and evaluated with the comet assay and 2 min was found to give damage DNA that could be evaluated with the comet assay with no induction of cell death. Unexposed cells were left without growth medium for 2 min. After UV light exposure, fresh growth medium was added and supplemented with $2.0 \mu M$ Lfcin $_{4-14}$ or PBS. Cells were harvested by trypsinization 24,48 , or 
$72 \mathrm{~h}$ after UV light exposure. Cells not exposed to UV light were cultivated in parallel and denoted unexposed.

\section{Comet Assay}

The comet assay was performed as previously described (Alm et al., 1999; Johansson et al., 2008). Cells were harvested and the cell number was determined by counting in a hemocytometer. Importantly, the duration of the trypsinization was limited to exactly $10 \mathrm{~min}$, as trypsin itself can induce DNA damage. Cells were pelleted by centrifugation at $700 \times g$ for $5 \mathrm{~min}$ at $4^{\circ} \mathrm{C}$. The pellet was resuspended in PBS to a concentration of 20,000 cells $/ \mu \mathrm{L}$. Thirty microliters of cell suspension was added to $1 \mathrm{~mL}$ of $1 \%$ low-melting agarose (NuSieve GTG; Lonza Group Ltd., Basel, Switzerland) in PBS kept at $37^{\circ} \mathrm{C}$. Seventy microliters of the resulting cell-agarose mixture was cast on a $24 \times 60$ GelBond membrane (Lonza Rockland Inc., Rockland, ME). Before incubation, an additional membrane was placed on top of the gel, forming a sandwich with the gel in between. The sandwiches were incubated at $4^{\circ} \mathrm{C}$ for 10 min, allowing the gel to solidify. The upper GelBond membrane was removed and an additional layer of pure agarose gel was added. The new sandwich was incubated $10 \mathrm{~min}$ at $4^{\circ} \mathrm{C}$. The upper GelBond membrane was removed and the solidified gel was incubated in lysis buffer [10\% dimethyl sulfoxide (DMSO), $1 \%$ Triton $\mathrm{X}-100,10 \mathrm{~m} M$ Tris $\mathrm{pH} 10$, and $2.5 \mathrm{M} \mathrm{NaCl}$ for $1 \mathrm{~h}$. The gels were incubated in electrophoresis buffer with high $\mathrm{pH}(300 \mathrm{~m} M \mathrm{NaOH}$ and $1 M$ EDTA, $\mathrm{pH} 8)$ to denature the DNA. The high $\mathrm{pH}$ implies that both double- and single-strand DNA breaks were detected. The gels were subjected to $30 \mathrm{~V}$ and $0.45 \mathrm{~A}$ for $30 \mathrm{~min}$. After electrophoresis, the gels were washed in neutralization buffer, allowing the complementary single-stranded DNA fragments to reform to double-stranded DNA. Finally, DNA was stained with ethidium bromide $(10 \mu \mathrm{g} / \mathrm{mL}$ in PBS), and the samples photographed with a fluorescence microscope [Olympus AX70 (Olympus America Inc., Center Valley, PA) equipped with a Nikon DS-RI1 camera (Nikon Instruments Inc., Melville, NY)]. For each sample, 140 cells were analyzed for tail moment (TMOM) using CometScore freeware (TriTek Corp., Sumerduck, VA). Experiments were repeated 4 to 6 times. The TMOM is the product of the percentage of DNA found in the tail and the tail length and is used as an indicator of DNA damage.

\section{Western Blot Analysis}

Cells for Western blot analysis were harvested by trypsinization, counted in a hemocytometer, and pel- leted at $700 \times g$ for $10 \mathrm{~min}$ at $4^{\circ} \mathrm{C}$. The cells were diluted in sample buffer $\left(300 \mu \mathrm{L}\right.$ per $10^{6}$ cells; 62.5 $\mathrm{m} M$ Tris- $\mathrm{HCl}, \mathrm{pH} 6.8,20 \%$ glycerol, $2 \%$ SDS, and $5 \%$ $\beta$-mercaptoethanol), sonicated, heated at $95^{\circ} \mathrm{C}$ for 6 min, and put on ice immediately after. Aliquots containing 50,000 cells were loaded in the wells of precast sodium dodecyl sulfate polyacrylamide gels (10\%) from Invitrogen (Life Technologies Inc., Carlsbad, CA). Electrophoresis was performed in an XCell SureLock Mini-Cell electrophoresis system and subsequent blotting by iBlot Dry Blotting System (Invitrogen). The membranes were then blocked with $5 \%$ dry milk in $0.05 \%$ Tween-20 in PBS before overnight incubation with the primary antibody. Antibodies against human cyclin B1 (554176) and the proapoptotic protein Bcell lymphoma 2-associated X protein (Bax; 554104) were purchased from B D Pharmingen Inc. (San Diego, CA). Antibodies against human cyclin E1 (sc-247) and survivin (sc-17779) were purchased from Santa Cruz Biotechnology Inc. (Santa Cruz, CA). Antibodies against centrin 3 (ab54531), checkpoint kinase 1 (Chk1; ab3306), structure-specific flap endonuclease 1 (FEN-1; ab17993), murine double minute 2 (MDM2; ab16895) and peroxisome proliferator-activated receptor- $\gamma$ (PPAR- $\gamma$; ab3409) were purchased from Abcam PLC (Cambridge, UK). The antibody against human proliferating cell nuclear antigen (PCNA; M 0879) was purchased from Dako Denmark A/S (Glostrup, Denmark). The antibody against human $\gamma$-H2AX (2577L) was purchased from Cell Signaling Technology Inc. (Boston, MA). Horseradish peroxidase-conjugated goat anti-mouse immunoglobulin was used as a secondary antibody (P0447; Dako Denmark A/S). The advanced enhanced chemiluminescence protein detection reagent was used according to the manufacturer's protocol (Amersham Biosciences Ltd., Buckinghamshire, UK). The ChemiDoc XRS system (Bio-Rad Inc., Hercules, CA) was used for the imaging and the software Quantity One (Bio-Rad Inc.) was used for the analysis of the bands. The intensities of the bands were calculated as a percentage of the control.

\section{Immunocytochemistry}

Cells used for immunocytochemistry were seeded in Petri dishes and the cell layers were washed with PBS before fixation in $3.7 \%$ formaldehyde for $15 \mathrm{~min}$. The cells were washed and areas (approximately 1.5 $\mathrm{cm}^{2}$ ) were demarcated with a hydrophobic pen. Blocking of cells in the areas was performed with Human TruStain FcX (BioLegend Inc., San Diego, CA) and then primary antibody in PBS with $0.05 \%$ Tween- 100 was added. The Petri dishes were incubated with pri- 
mary antibody $(\gamma-\mathrm{H} 2 \mathrm{AX}$ or $\mathrm{Chk} 1)$ overnight at $4^{\circ} \mathrm{C}$. After washing, the secondary antibody was added. Alexa Fluor 594-conjugated (A11037) or Alexa Fluor 488-conjugated (A11029) were both purchased from Invitrogen. The DNA-binding fluorescent molecule bisbenzimide (Sigma-Aldrich Co.; $1 \mu \mathrm{g} / \mathrm{mL}$ ) was used to visualize the cell nuclei. Slides were coverslipped using glycerol-PBS (1:1) and sealed with nail polish and thereafter examined and photographed with a fluorescence microscope (Olympus AX70 equipped with a Nikon DS-RI1 camera). Several images were captured for each treatment group and the number of cells expressing $\gamma-\mathrm{H} 2 \mathrm{AX}$ was expressed as a percentage of the total cell number. A total of 300 cells was counted in each treatment group.

\section{Cell Cycle Phase Distribution}

Cells were prepared for flow cytometric analysis as previously described (Fredlund et al., 1994). The flow cytometric analysis was performed using an Ortho Cytoron Absolute flow cytometer (Ortho Diagnostic Systems Inc., Raritan, NJ). The data were analyzed using Multi2D and MultiCycle software programs (Phoenix Flow Systems, San Diego, CA).

\section{Statistical Analysis}

A 2-tailed unpaired Student's t-test was used for the statistical evaluation of significance of the TMOM values and the densitometric scanning of the Western blots. Statistical analyses were performed in Microsoft Office Excel 2003 (Microsoft Corp., Redmond, WA).

\section{RESULTS}

\section{Comet Assay}

Initially experiments were performed with cells treated with $2.0 \mu \mathrm{M} \mathrm{Lfcin}{ }_{4-14}$ alone to ensure that Lf$\operatorname{cin}_{4-14}$ per se did not cause any DNA damage (data not shown). Treatment with $2.0 \mu M \operatorname{Lfcin}_{4-14}$ for $48 \mathrm{~h}$ did not cause DNA damage, whereas UV light caused DNA damage. The TMOM of cells treated with $2.0 \mu M$ Lfcin $_{4-14}$ was the same as that of the control, whereas the TMOM of cells exposed to UV light was $230 \%$ that of the control. Thereafter, we investigated the effect of Lfcin $_{4-14}$ on UV light-induced DNA damage (Figure 1). Images of the comets of the different treatment groups are shown in Figure 1A. Visual inspection showed that only a few distinct comets were found in unexposed cultures. Ultraviolet light exposure resulted in a significant increase in the number of comets and treatment with Lfcin $_{4-14}$ of UV light-exposed cells reduced the number of comets. The distributions of DNA in the tails and the lengths of the tails of the comets were evaluated using CometScore freeware (TriTek Corp.). Figure 1B shows the percentage of DNA in tail versus tail length. This data was used to calculate TMOM of individual comets, which is defined as the percentage of DNA in tail multiplied by tail length (Figure 1C). The comets were consecutively given an identification number with increasing TMOM (Figure 1C). The percentage of undamaged comets, defined as having TMOM $\leq 0.05$, was calculated (Figure 1D). Ultraviolet light-exposed cultures had fewer undamaged comets and treatment with $\mathrm{Lfcin}_{4-14}$ increased the percentage of undamaged comets. The mean TMOM of the 50 comets having the highest TMOM values was calculated for unexposed as well as for UV light-exposed cells that were cultivated in the absence (control) or presence of $\mathrm{Lfcin}_{4-14}$ (Figure 1D). The Student's $t$-test used to compare the comets of the control and Lfcin $_{4-14}$-treated cells showed that the latter had a significantly lower TMOM value. Statistical evaluation comparing the TMOM of UV light-exposed cells incubated in the absence (control)

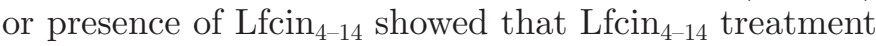
resulted in a statistically significant reduction of DNA damage at 24, 48, and $72 \mathrm{~h}$ of treatment (Table 1 ).

\section{Protein Expression}

As Lfcin $_{4-14}$ treatment reduced the TMOM of cells exposed to UV light, we continued to study the levels of some common proteins involved in DNA damage and repair using Western blot. In addition, the expression of proteins involved in cell cycle regulation, survival, and apoptosis were studied. Interpretation of the data was based on 3 or more independent experiments.

Survivin, B-cell lymphoma 2 (Bcl-2), and Bax are involved in the regulation of cell survival and cell death, with the 2 former being antiapoptotic, whereas the later is proapoptotic. Lactoferricin ${ }_{4-14}$ treatment of UV light-exposed cells resulted in levels of survivin, Bcl-2, and Bax that were not significantly different from those in totally unexposed cells (Figure 2A and B). However, the levels of survivin, Bax, and Bcl-2 were significantly higher in cells exposed to UV light (control) compared with cells exposed to UV light and then treated with Lfcin $_{4-14}$ (Figure 2A and C). Cyclin B1 is involved in the regulation of $\mathrm{G}_{2} / \mathrm{M}$ progression. The expression of cyclin B1 was significantly higher in the UV light-exposed (control) cells compared with UV light-exposed cells treated with $\mathrm{Lfcin}_{4-14}$, although the level of cyclin B1 in the former was the same as in unexposed cells (Figure 


\section{A Unexposed}

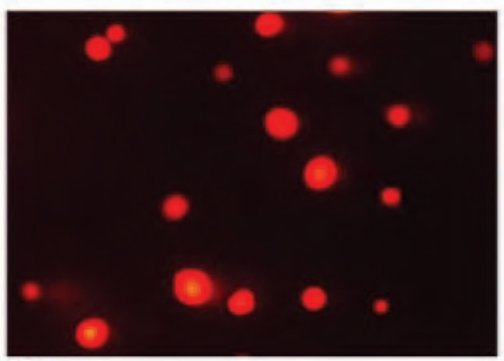

B

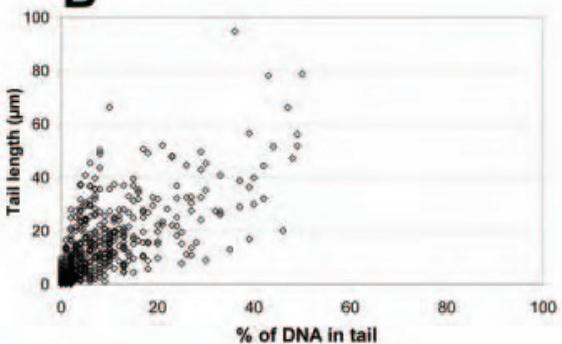

\section{UV light-exposed}
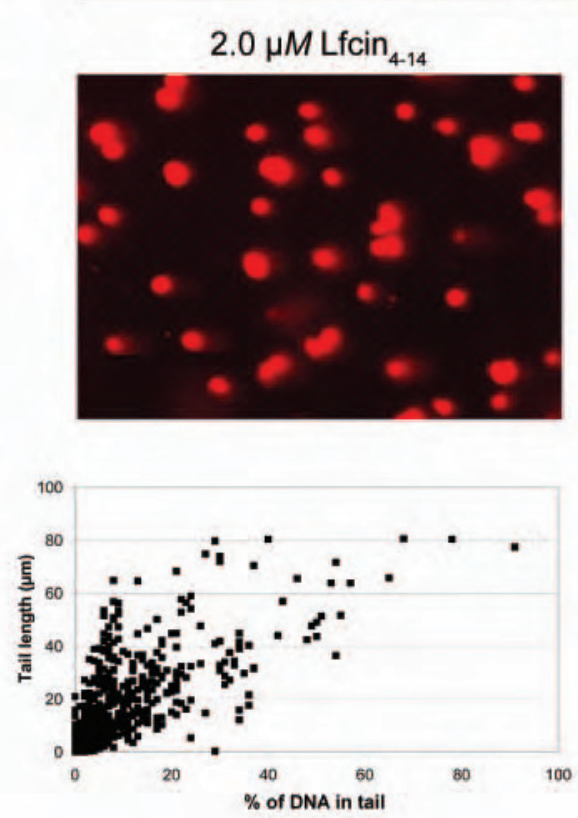
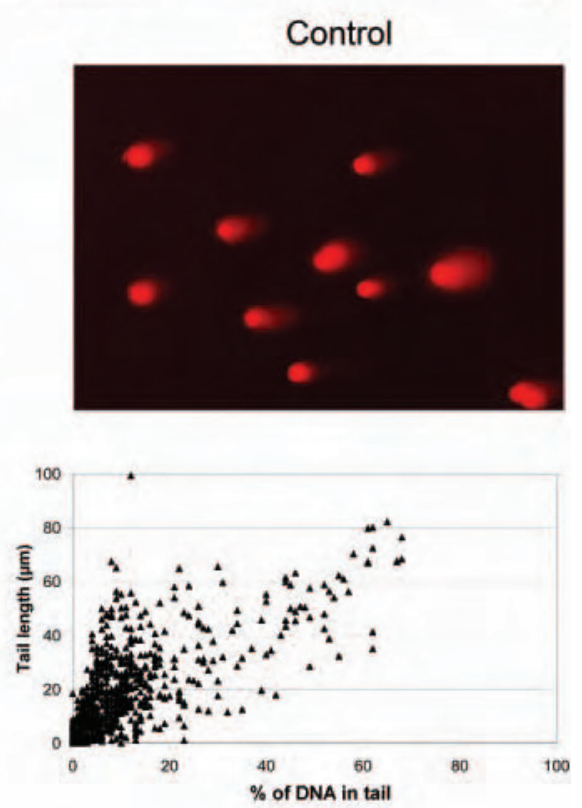

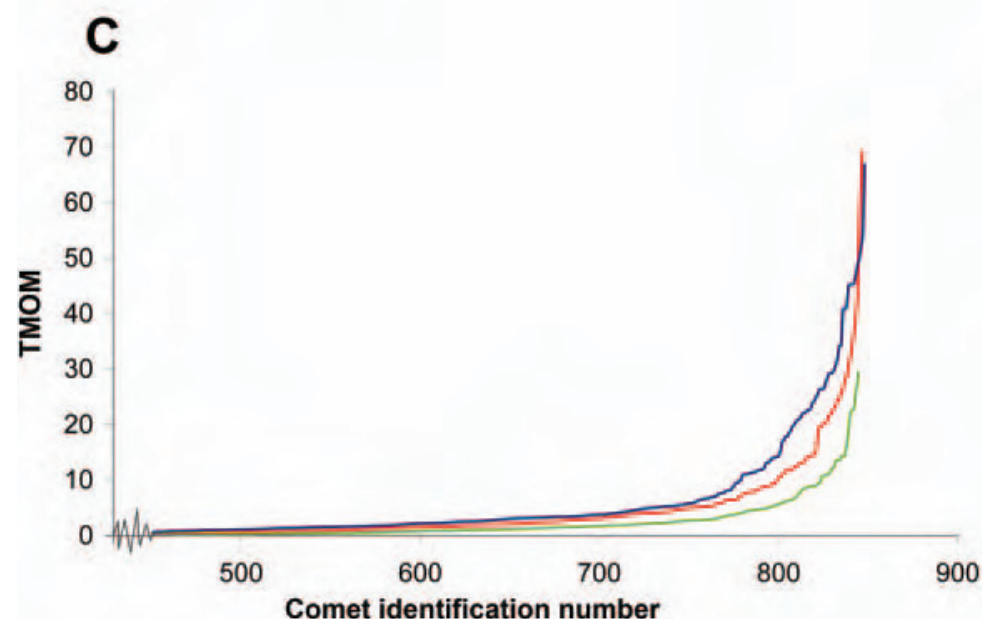

\begin{tabular}{lcc} 
D & $\begin{array}{c}\text { Undamaged } \\
\text { comets (\%) }\end{array}$ & $\begin{array}{c}\text { Highest mean } \\
\text { TMOM value }^{\mathrm{b}}\end{array}$ \\
\hline Unexposed & $54 \pm 10$ & $13 \pm 8$ \\
\hline $\begin{array}{l}\text { UV light- } \\
\text { exposed }\end{array}$ & & \\
$\begin{array}{l}2.0 \mu M \text { Lfcin }_{4 \cdot 14} \\
\text { Control }\end{array}$ & $42 \pm 8^{\circ}$ & $23 \pm 15^{d}$ \\
\end{tabular}

aComets with TMOM $\leq 0.05$ measured by the comet assay were defined as undamaged. Expressed as \% of all comets evaluated (849). Mean \pm SD from 5-6 experiments. bMean TMOM value of 50 comets with highest TMOM. c.d $P<0.05$ compared with control.

Figure 1. Lactoferricin ${ }_{4-14}\left(\operatorname{Lfcin}_{4-14}\right)$ treatment of Caco-2 cells reduced UV light-induced DNA damage evaluated with the comet assay Twenty-four hours after seeding, DNA damage was induced by exposing the cells to UV light $\left(3.18 \pm 0.2 \mathrm{~mW} / \mathrm{cm}^{2}\right)$ for $2 \mathrm{~min}$. Thereafter, cells were incubated for $48 \mathrm{~h}$ in the absence (control) or presence of $2.0 \mu M$ Lfcin $_{4-14}$. Totally unexposed cells were also cultivated in parallel. Cells were harvested by trypsinization and the comet assay was performed as previously described (Alm et al, 1999; Johansson et al., 2008). (A) Representative fluorescence microscopy images of comets obtained by the comet assay of unexposed cells and of UV light-exposed cells grown in the absence (control) or presence of $\mathrm{Lfcin}_{4-14}$. The DNA damage results in a comet with head and tail, whereas unharmed DNA results in a round head. (B) Percentage of DNA in tail on the x-axis versus tail length on the $\mathrm{y}$-axis for individual cells detected by the comet assay of unexposed cells and of UV light-exposed cells grown in the absence (control) or presence of Lfcin ${ }_{4-14}$. (C) Tail moment (TMOM, percentage of DNA in tail multiplied by tail length) for 849 individual comets of the different treatment groups. Only comets with TMOM more than 0.04 are shown in the image. Green line (light gray in print version) = unexposed cells; blue line (black line in print version) = UV light-treated cells; red line (dark gray in print version) $=\mathrm{UV}$ light-treated cells incubated in the presence of $\mathrm{Lfcin}_{4-14}$. (D) Comparison of percentage undamaged cells (where the TMOM is lower than 0.05) and mean TMOM of the 50 comets with the highest TMOM values. Color version available in the online PDF.

$2 \mathrm{~A}$ and $\mathrm{C})$. Also, the expression of cyclin E1 was significantly higher in the UV light-exposed (control) cells compared with UV light-exposed and Lfcin $_{4-14}$-treated cells (Figure 2A and C).
The FEN-1 expression was significantly lower in UV light-exposed cells that had been grown for $48 \mathrm{~h}$ in the absence or presence of $\mathrm{Lfcin}_{4-14}$ compared with unexposed cells (Figure 2A and B). However, Lfcin $_{4-14}$ 


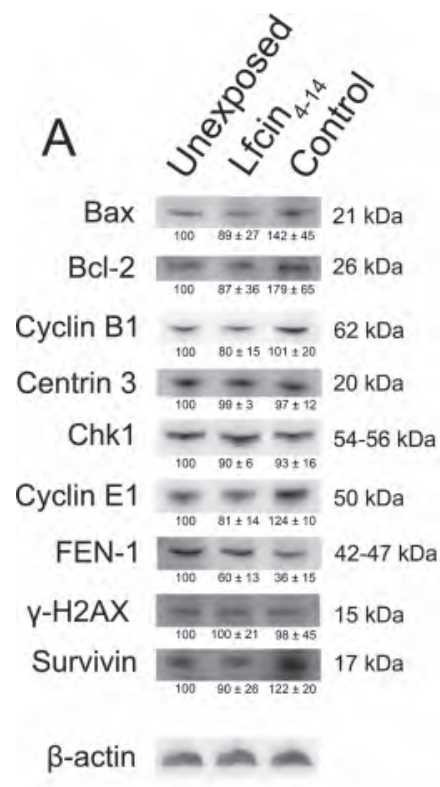

B Compared with unexposed

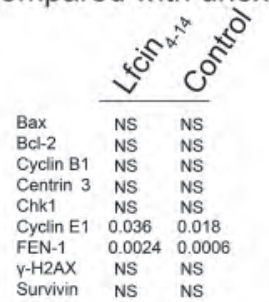

C Compared with control

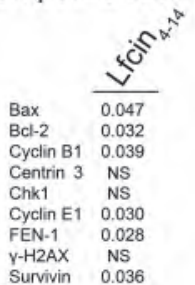

Figure 2. Protein expression in UV light-exposed Caco-2 cells after 48-h incubation in the absence or presence of $2.0 \mu \mathrm{M}$ lactoferricin $_{4-14}$ $\left(\operatorname{Lfcin}_{4-14}\right)$. Twenty-four hours after seeding, DNA damage was induced by exposing the cells to UV light $\left(3.18 \pm 0.2 \mathrm{~mW} / \mathrm{cm}^{2}\right)$ for $2 \mathrm{~min}$. Thereafter, cells were incubated for $48 \mathrm{~h}$ in the absence (control) or presence of $2.0 \mu \mathrm{M} \mathrm{Lfcin} \mathrm{L}_{4-14}$. Totally unexposed cells were also cultivated in parallel. (A) Western blot was used to investigate protein levels. The intensities of the bands are presented as percentage of unexposed (mean $\pm \mathrm{SD}, \mathrm{n}=3-6$ ). (B) Statistics calculated with the Student's paired $t$-test for the protein levels of UV light-exposed cells incubated in the absence (control) or presence of $\operatorname{Lfcin}_{4-14}$ compared with unexposed cells. (C) Statistics calculated with the Student's paired $t$-test for the protein levels of UV light-exposed cells treated with $\mathrm{Lfic}_{4-14}$ compared with UV light-exposed control cells. The data are representative of 3 independent cultures from 3 independent experiments. Bax = B-cell lymphoma 2-associated X protein; Bcl-2 = B-cell lymphoma 2 ; Chk1 = checkpoint kinase $1 ; \mathrm{FEN}-1=$ structure-specific flap endonuclease 1 .

treatment of UV light-treated cells resulted in a significant increase in the FEN-1 level compared with UV light-exposed control cells (Figure 2A and C).

The levels of centrin 3, Chk1, and $\gamma$-H2AX were the same in unexposed cells and UV light-exposed cells incubated in the absence or presence of $\mathrm{Lfcin}_{4-14}$ for 48 $\mathrm{h}$ (Figure 2A, B and C). We also investigated the levels of MDM2, PCNA, and PPAR- $\gamma$ and they were all unaffected by UV light exposure and no differences could be seen between the UV light-exposed cells treated with Lfcin $_{4-14}$ compared with the untreated cells (not shown).

\section{Immunofluorescence Microscopy}

Immunocytochemical staining was used to study the expression of proteins involved in DNA damage and repair. Twenty-four hours after UV light exposure, a significant increase could be seen in $\gamma$-H2AX expression, indicating DNA double-strand breaks induced by the UV light in both Lfcin $_{4-14}$-treated and control cells (Figure 3). However, the number of cells expressing $\gamma-\mathrm{H} 2 \mathrm{AX}$ was significantly decreased by $\mathrm{Lfcin}_{4-14}$ treatment compared with the control.

Checkpoint kinase 1 is an important regulator of the $\mathrm{G}_{2} / \mathrm{M}$ checkpoint that can be activated (e.g., in response to DNA damage caused by UV light or ionizing radiation). Double-strand breaks may lead to activation of Chk1, via ATM (Stracker et al., 2009). As a response to DNA damage, Chk1 is relocalized from the nucleus to the cytoplasm and from there, a portion localizes to the interphase centrosomes (Stracker et al., 2009). Western blot analysis of the Chk1 level showed that it was the same in all treatment groups at $48 \mathrm{~h}$ of treatment (Figure 2). However, immunofluorescence microscopy showed an increased level of Chk1 in the cytoplasm of UV light-exposed cells treated with Lfcin $_{4-14}$ (Figure 4).

\section{Cell Cycle Phase Distribution}

The cell cycle phase distribution was similar in all treatment groups (not shown). No sub- $\mathrm{G}_{1}$ peak, indicative of cell death, was observed in any of the treatment groups (not shown).

\section{DISCUSSION}

We have previously shown that the bovine milk peptide $\operatorname{Lfcin}_{4-14}$ decreased the proliferation rate of

Table 1. Tail moment (TMOM; mean \pm SD) as percentage of control in Caco-2 cells incubated in the absence or presence of $2.0 \mu \mathrm{M}$ lactoferricin $_{4-14}\left(\operatorname{Lfcin}_{4-14}\right)$ after exposure to UV light detected by the comet assay

\begin{tabular}{lcc}
\hline & \multicolumn{2}{c}{ TMOM (\% of unexposed) } \\
\cline { 2 - 3 } Incubation & $2.0 \mu M$ Lfcin $_{4-14}$ & Control \\
\hline $24 \mathrm{~h}^{2}$ & $149 \pm 44^{* *}$ & $203 \pm 54$ \\
$48 \mathrm{~h}^{3}$ & $159 \pm 46^{* *}$ & $216 \pm 88$ \\
$72 \mathrm{~h}^{2}$ & $205 \pm 20^{*}$ & $231 \pm 26$ \\
\hline
\end{tabular}

${ }^{1}$ At time 0 , cells were trypsinized and seeded in Petri dishes. After a 24-h attachment period, DNA damage was induced by exposure to UV light $\left(3.18 \pm 0.2 \mathrm{~mW} / \mathrm{cm}^{2}\right)$ for $2 \mathrm{~min}$. Thereafter, cells were incubated in the absence (control) or presence of $2.0 \mu M \mathrm{Lfcin}_{4-14}$ for 24,48 , or 72 h. In parallel, totally unexposed cells were cultivated and DNA damage was evaluated using the comet assay. For the statistical evaluation, a Student's unpaired $t$-test was done. The data of cells treated with UV light and then incubated in the absence or presence of $\operatorname{Lfcin}_{4-14}$ were compared with those of totally unexposed cells, which was defined as $100 \%$. The TMOM $=\%$ DNA in tail $\times$ tail length.

${ }^{2}$ Data from 4 independent experiments with $\mathrm{n}=140$ comets in each.

${ }^{3}$ Data from 6 independent experiments with $\mathrm{n}=140$ to 150 comets in each.

${ }^{*} P<0.05$ compared with control; ${ }^{* *} P<0.01$ compared with control. 


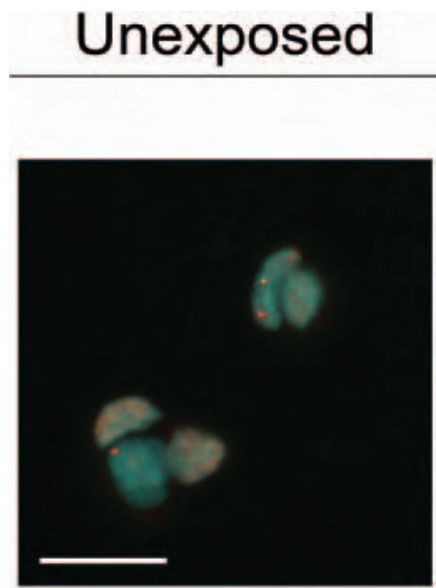

$40 \pm 11$

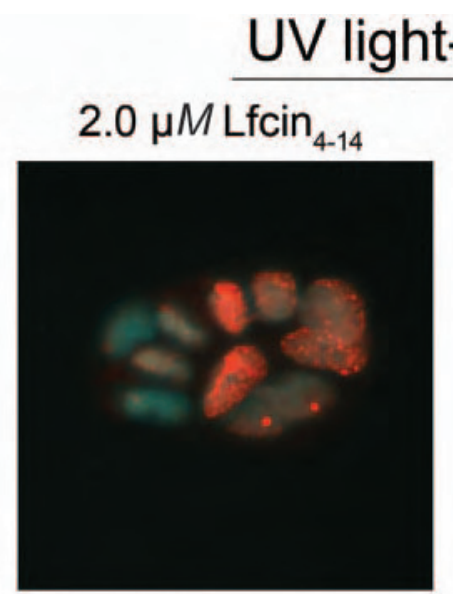

$70 \pm 10$ **
Control

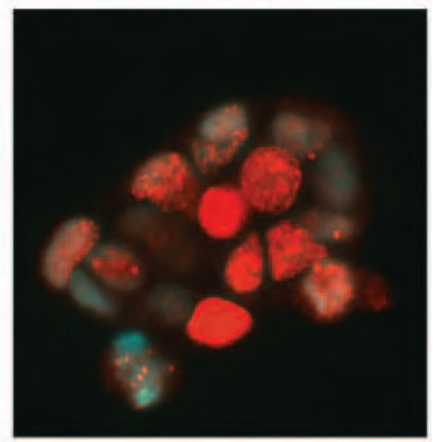

$80 \pm 8^{* *}$

Cells expressing $\mathrm{y}-\mathrm{H} 2 \mathrm{AX}(\%)$

Figure 3. Lactoferricin ${ }_{4-14}\left(\operatorname{Lfcin}_{4-14}\right)$ treatment reduced the number of cells expressing $\gamma$-H2AX in Caco-2 cells $24 \mathrm{~h}$ after exposure to UV light. Twenty-four hours after seeding, DNA damage was induced by exposing the cells to UV light $\left(3.18 \pm 0.2 \mathrm{~mW} / \mathrm{cm}^{2}\right)$ for $2 \mathrm{~min}$. Thereafter, cells were incubated for $24 \mathrm{~h}$ in the absence (control) or presence of $2.0 \mu M$ Lfcin $_{4-14}$. Totally unexposed cells were also cultivated in parallel. Cells were fixed in 3.7\% paraformaldehyde and incubated with primary $\gamma$-H2AX antibody and with secondary Alexa 594-conjugated antibody (Invitrogen, Life Technologies Inc., Carlsbad, CA). The cell nuclei were stained with bisbenzimide. The samples were examined in and photographed with a fluorescence microscope equipped with a camera. Significantly more cells expressed $\gamma$-H2AX in cultures exposed to UV light compared with unexposed cultures $\left({ }^{* *} P<0.01\right)$. The number of cells expressing $\gamma$-H2AX was significantly decreased in the Lfcin s $_{4-14}$-treated cultures compared with control cultures $(* * P<0.01)$. The images shown are representative of 3 independent cultures from 3 independent experiments. Scale bar $=20 \mu \mathrm{m}$. Color version available in the online PDF.

human colon cancer cells by prolonging the $\mathrm{S}$ phase (Freiburghaus et al., 2009). In the current study, we showed that the concentration of $\mathrm{Lfcin}_{4-14}$ used in our study did not induce any DNA damage compared with untreated control cells. We have previously hypothesized that the prolongation of the cell cycle in Caco-2 cells as a result of $\mathrm{Lfcin}_{4-14}$ treatment may give the cells extra time for DNA repair (Freiburghaus et al.,
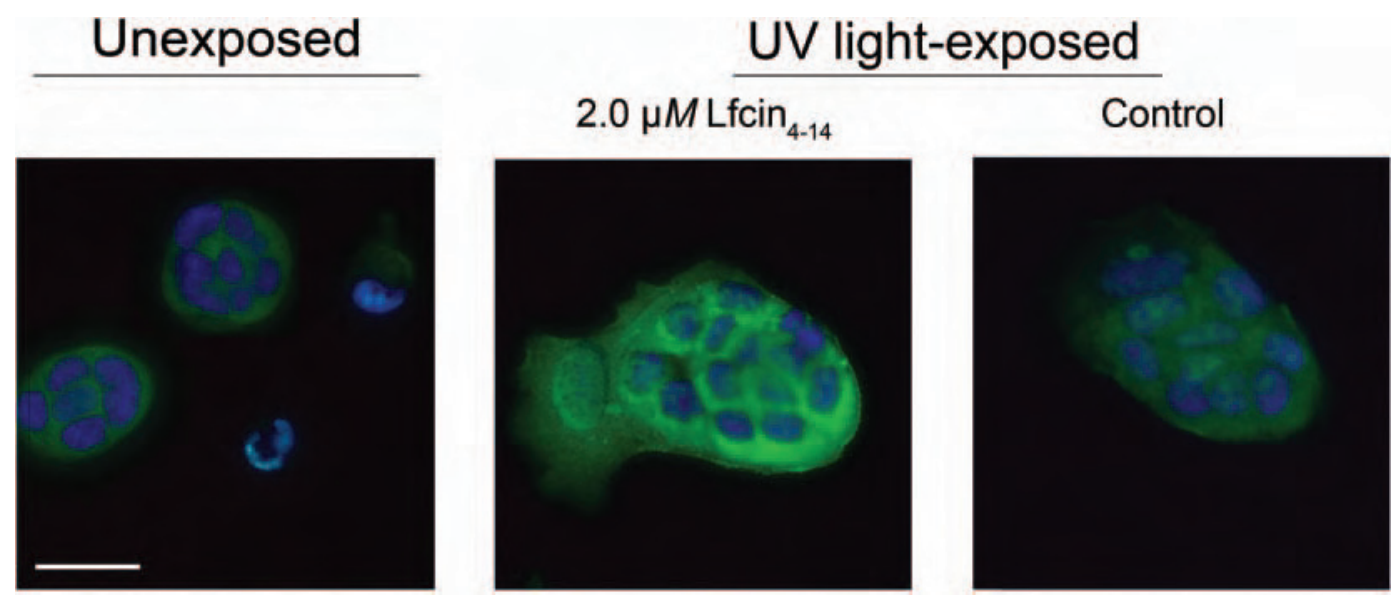

Figure 4. Increased expression of checkpoint kinase 1 (Chk1) in the cytoplasm of Caco-2 cells 24 h after exposure to UV light and lactofer$\operatorname{ricin}_{4-14}\left(\right.$ Lfcin $\left._{-14}\right)$. Twenty-four hours after seeding, DNA damage was induced by exposing the cells to UV light $\left(3.18 \pm 0.2 \mathrm{~mW} / \mathrm{cm}^{2}\right)$ for 2 min. Thereafter, cells were incubated for $24 \mathrm{~h}$ in the absence (control) or presence of $2.0 \mu M$ Lfcin $_{4-14}$. Totally unexposed cells were also cultivated in parallel. Cells were fixed with 3.7\% paraformaldehyde and incubated with primary Chk1 antibody and with secondary Alexa 488-conjugated antibody (Invitrogen, Life Technologies Inc., Carlsbad, CA). The cell nuclei were stained with bisbenzimide. The samples were examined in and photographed with a fluorescence microscope equipped with a camera. A higher expression of Chk1 was present in the cytoplasm of the

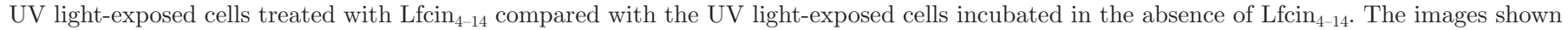
are representative of 3 independent cultures from 3 independent experiments. Scale bar $=20 \mu \mathrm{m}$. Color version available in the online PDF. 
2009). Of course, it is not beneficial that cancer cells get time for repair but we have used this as a model system. It should be remembered that cancer cells, in general, have defects in the DNA repair mechanisms (Hanahan and Weinberg, 2000). Thus, our observation presumably has a greater effect on normal cells than on cancer cells.

Indeed, the UV light-induced DNA damage as detected by the comet assay was decreased in Caco-2 cells treated with $2.0 \mu \mathrm{M} \mathrm{Lfcin}_{4-14}$ compared with the untreated control cells. The differences were small but significant. These results are supported by a significant decrease in cells expressing $\gamma$-H2AX at $24 \mathrm{~h}$ of $\mathrm{Lfcin}_{4-14}$ treatment compared with the control cells. The phosphorylation of serine 139 on $\mathrm{H} 2 \mathrm{AX}$ to form $\gamma$-H2AX is one of the earliest responses to DNA double-strand breaks, which may explain why the difference cannot be observed by Western blot $48 \mathrm{~h}$ after induced DNA damage. This modification of H2AX is observed widely around the double-strand break and has been proposed to play numerous roles in break recognition and repair (Fillingham et al., 2006).

As Lfcin $_{4-14}$ reduced the DNA damage compared with the control, we expected the survival proteins survivin and Bcl-2 to be higher in Lfcin $_{4-14}$-treated cells than in control cells. However, that was not the case. The expression of the proapoptotic protein Bax, however, showed the expected pattern with a higher level in control cells than in Lfcin $_{4-14}$-treated cells. Bcell lymphoma 2 and Bax belong to the same Bcl-2 family and they have opposing effects, whereas the effect of survivin is not supposed to be related to Bax and Bcl-2 (Duan et al., 2005). On the other hand, there are other ways of interpreting our data. Lactoferricin $_{4-14}$ treatment may have had beneficial effects not requiring changes in expression of any of these proteins, as their levels were not significantly altered compared with cells that were not exposed to UV light at all. Exposure of MCF-7 breast cancer cells to low UV light $\left(50 \mathrm{~J} / \mathrm{m}^{2}\right)$ resulted in increased survivin expression, and it also appeared to protect the cells from apoptosis (Asumen et al., 2010). At higher UV light doses, they did not see increased survivin levels and apoptosis was increased.

We cannot entirely exclude the presence of cells in early apoptosis, and a few comets with a tiny or undetectable head and a faint tail were observed, appearances characteristic for apoptotic cells (Olive et al., 1998; Husseini et al., 2005). However, a large quantity of apoptotic cells would have been visible as a large sub- $\mathrm{G}_{1}$ population in cell cycle phase distribution. No such population was seen and the majority of the cells had the characteristics of viable cells with DNA damage (Olive et al., 1998; Husseini et al., 2005).
The expression of Chk1 was studied using immunofluorescence microscopy $24 \mathrm{~h}$ after UV light exposure and also with Western blot $48 \mathrm{~h}$ after UV light exposure. The images from the immunofluorescence microscopy indicate a higher expression of Chk1 in cells treated with Lfcin $_{4-14}$ for $24 \mathrm{~h}$ after UV light exposure compared both with the unexposed control cells and the untreated cells exposed to UV light. As overexpression of Chk1 has been shown to cause cell cycle arrest in the $\mathrm{G}_{2}$ phase, due to DNA damage in the $\mathrm{S}$ phase or $\mathrm{G}_{2}$ phase (Tapia-Alveal et al., 2009), the high expression of Chk1 may support the hypothesis that $\mathrm{Lfcin}_{4-14}$ gives the cell more time to repair DNA lesions. In our study, we did not find an increased $G_{2}$ phase population in the investigation of cell cycle phase distribution, yet clearly more cytoplasmic Chk1 was present in $\operatorname{Lfcin}_{4-14}$-treated cells than in control cells.

Caco-2 cells are colon cancer cells and, of course, it is not beneficial if cancer cells in the body are stimulated to repair their DNA more efficiently by food components. On the other hand, we must also be aware of the fact that food components that act beneficially may potentially have a beneficial effect on cancer cells, as they after all derive from normal cells. In cancer cells, Lfcin $_{4-14}$ may not have a lasting beneficial effect in cancer cells because the DNA repair systems generally are defective. A possible differential effect of $\mathrm{Lfcin}_{4-14}$ in normal cells and cancer cells has to be further investigated. Importantly, normal $p 53$ is required to maintain proper and efficient DNA repair. The majority of human cancers carry a nonfunctional p53 gene, which is also the case for Caco-2 cells (Karczewski et al., 2000).

\section{CONCLUSIONS}

Using the comet assay, we found that $\mathrm{Lfcin}_{4-14}$ treatment resulted in decreased DNA strand breaks in UV light-irradiated Caco-2 cells. We believe that this observation is of importance for normal cells and the possibility of $\operatorname{Lfcin}_{4-14}$ being part of the cancer preventive effect of milk.

\section{ACKNOWLEDGMENTS}

We thank Pär-Ola Bendahl from the Department of Oncology (Lund University, Lund, Sweden) for help with the statistical evaluation and Jason Beech from the Department of Solid State Physics (Lund University) for help with measurements of UV light. This work was supported by grants from The Swedish Research Council for Environment, Agricultural Sciences, and Spatial Planning (FORMAS, Stockholm, Sweden) and Johanna Anderssons stiftelse för främjande av naturligt levnadssätt (Lund, Sweden). 


\section{REFERENCES}

Ahmed, F. E. 2004. Effect of diet, life style, and other environmental/ chemopreventive factors on colorectal cancer development and assessment of the risks. J. Environ. Sci. Health C Environ. Carcinog. Ecotoxicol. Rev. 22:91-147.

Alm, K., P. Berntsson, and S. M. Oredsson. 1999. Topoisomerase II is nonfunctional in polyamine-depleted cells. J. Cell. Biochem. $75: 46-55$.

Arnold, R. R., M. Brewer, and J. J. Gauthier. 1980. Bactericidal activity of human lactoferrin: Sensitivity of a variety of microorganisms. Infect. Immun. 28:893-898.

Asumen, M. G., T. V. Ifeacho, L. Cockerham, C. Pfandl, and N. R. Wall. 2010. Dynamic changes to survivin subcellular localization are initiated by DNA damage. Oncol. Targets Ther. 3:129-137.

Bellamy, W., M. Takase, K. Yamauchi, H. Wakabayashi, K. Kawase, and M. Tomita. 1992. Identification of the bactericidal domain of lactoferrin. Biochim. Biophys. Acta 1121:130-136.

Berkhout, B., J. L. B. van Wamel, L. Beljaars, D. K. F. Meijer, S. Visser, and R. Floris. 2002. Characterization of the anti-HIV effects of native lactoferrin and other milk proteins and proteinderived peptides. Antiviral Res. 55:341-355.

Cho, E., S. A. Smith-Warner, D. Spiegelman, W. L. Beeson, P. A. van den Brandt, G. A. Colditz, A. R. Folsom, G. E. Fraser, J. L. Freudenheim, E. Giovannucci, R. A. Goldbohm, S. Graham, A. B. Miller, P. Pietinen, J. D. Potter, T. E. Rohan, P. Terry, P. Toniolo, M. J. Virtanen, W. C. Willett, A. Wolk, K. Wu, S.-S. Yaun, A Zeleniuch-Jacquotte, and D. J. Hunter. 2004. Dairy foods, calcium, and colorectal cancer: A pooled analysis of 10 cohort studies. J. Natl. Cancer Inst. 96:1015-1022.

Damiens, E., I. El Yazidi, J. Mazurier, I. Duthille, G. Spik, and Y. Boilly-Marer. 1999. Lactoferrin inhibits $\mathrm{G}_{1}$ cyclin-dependent kinases during growth arrest of human breast carcinoma cells. J. Cell. Biochem. 74:486-498.

Duan, X.-X., J.-S. Ou, Y. Li, J.-J. Su, C. Ou, C. Yang, H.-F. Yue, and K.-C. Ban. 2005. Dynamic expression of apoptosis-related genes during development of laboratory hepatocellular carcinoma and its relation to apoptosis. World J. Gastroenterol. 11:4740-4744.

Eliassen, L. T., G. Berge, A. Leknessund, M. Wikman, I. Lindin, C. Løkke, F. Ponthan, J. I. Johnsen, B. Sveinbjørnsson, P. Kogner, T. Flægstad, and $\varnothing$. Rekdal. 2006. The antimicrobial peptide, Lactoferricin $\mathrm{B}$, is cytotoxic to neuroblastoma cells in vitro and inhibits xenograft growth in vivo. Int. J. Cancer 119:493-500.

Ellison, R. T. 3rd, and T. J. Giehl. 1991. Killing of gram-negative bacteria by lactoferrin and lysozyme. J. Clin. Invest. 88:1080-1091.

Elwood, P. C., I. Givens, A. D. Beswick, A. M. Fehily, J. E. Pickering, and J. Gallacher. 2008. The survival advantage of milk and dairy consumption: An overview of evidence from cohort studies of vascular diseases, diabetes and cancer. J. Am. Coll. Nutr. $27: 723 \mathrm{~S}-734 \mathrm{~S}$

Fairbairn, D. W., P. L. Olive, and K. L. O'Neill. 1995. The comet assay: A comprehensive review. Mutat. Res. 339:37-59.

Fillingham, J., M.-C. Koegh, and N. J. Krogan. 2006. $\gamma$-H2AX and its role in double strand break repair. Biochem. Cell Biol. 84:568 577.

Foster, E. R., and J. A. Downs. 2005. Histone H2AX phosphorylation in DNA double strand repair. FEBS J. 272:3231-3240.

Fredlund, J. O., M. Johansson, B. Baldetorp, and S. M. Oredsson. 1994. Abnormal DNA synthesis in polyamine deficient cells revealed by bromodeoxyuridine-flow cytometry technique. Cell Prolif. 27:243-256.

Freiburghaus, C., B. Janicke, H. Lindmark-Månsson, S. M. Oredsson, and M. Paulsson. 2009. Lactoferricin treatment decreases the rate of cell proliferation of a human colon cancer cell line. J. Dairy Sci. 92:2477-2484.

Hanahan, D., and R. A. Weinberg. 2000. The hallmarks of cancer. Cell 100:57-70.
Husseini, G. A., K. L. O'Neill, and W. G. Pitt. 2005. The comet assay to determine the mode of cell death for the ultrasonic delivery of doxorubicin to human leukemia (HL-60 cells) from Pluronic p105 micelles. Technol. Cancer Res. Treat. 4:707-711.

Jing, W., J. S. Svendsen, and H. J. Vogel. 2006. Comparison of NMR structures and model-membrane interactions of 15-residue antimicrobial peptides derived from bovine lactoferricin. Biochem. Cell Biol. 84:312-326.

Johansson, V. M., S. M. Oredsson, and K. Alm. 2008. Polyamine depletion with two different polyamine analogues causes DNA damage in human breast cancer cell lines. DNA Cell Biol. 27:511-516.

Karczewski, J. M., J. A. M. Vet, D. Hessels, and J. Noordhoek. 2000. p53-Independent apoptosis induced by menadione in the human colon carcinoma cell line Caco-2. Ann. N. Y. Acad. Sci. 915:275278.

León-Sicairos, N., M. Reyes-López, C. Ordaz-Pichardo, and M. de la Garza. 2006. Microbial action of lactoferrin and lactoferricin and their synergistic effect with metronidazole in Entamoeba histolytica. Biochem. Cell Biol. 84:327-336.

Lynch, H. T., and A. de la Chapelle. 2003. Hereditary colorectal cancer. N. Engl. J. Med. 348:919-932.

Mader, J. S., A. Richardson, J. Salsman, D. Top, R. de Antueno, R. Duncan, and D. W. Hoskin. 2007. Bovine lactoferricin causes apoptosis in Jurkat T-leukemia cells by sequential permeabilization of the cell membrane and targeting of mitochondria. Exp. Cell Res. 313:2634-2650.

Min, S., and J. Krochta. 2005. Inhibition of Penicillium commune by edible whey protein films incorporating lactoferrin, lactoferrin hydrolysate, and lactoperoxidase systems. J. Food Sci. 70:M87M94.

Olive, P. L., P. J. Johnston, J. P. Banath, and R. E. Durand. 1998. The comet assay: A new method to examine heterogeneity associated with solid tumors. Nat. Med. 4:103-105.

Reinhardt, H. C., and M. B. Yaffe. 2009. Kinases that control the cell cycle in response to DNA damage: Chk1, Chk2, and MK2. Curr. Opin. Cell Biol. 21:245-255.

Stracker, T. H., T. Usui, and J. H. J. Petrini. 2009. Taking time to make important decisions: The checkpoint effector kinases Chk1 and Chk2 and the DNA damage response. DNA Repair (Amst.) 8:1047-1054.

Tapia-Alveal, C., T. M. Calonge, and M. J. O'Connell. 2009. Regulation of Chk1. Cell Div. 4:8. http://dx.doi.org/10.1186/1747-10284-8.

Troost, F. J., J. Steijns, W. H. M. Saris, and R.-J. M. Brummer. 2001. Gastric digestion of bovine lactoferrin in vivo in adults. J. Nutr. 131:2101-2104.

van Belzen, N. 2002. The role of lactoferrin in cancer prevention. Sci Aliments 22:461-468.

Vogel, H. J., D. J. Schibli, W. Jing, E. M. Lohmeier-Vogel, R. F. Epand, and R. M. Epand. 2002. Towards a structure-function analysis of bovine lactoferricin and related tryptophan- and argininecontaining peptides. Biochem. Cell Biol. 80:49-63.

Wakabayashi, H., M. Takase, and M. Tomita. 2003. Lactoferricin derived from milk protein lactoferrin. Curr. Pharm. Des. 9:12771287

World Cancer Research Fund/American Institute for Cancer Research. 2007. Food, nutrition, physical activity and the prevention of cancer: A global perspective. AICR, Washington, DC.

Yoo, Y.-C., S. Watanabe, R. Watanabe, K. Hata, K. Shimazaki, and I. Azuma. 1997. Bovine lactoferrin and lactoferricin, a peptide derived from bovine lactoferrin, inhibit tumor metastasis in mice. Jpn. J. Cancer Res. 88:184-190.

Zlatanova, J., T. C. Bishop, J.-M. Victor, V. Jackson, and K. van Holde. 2009. The nucleosome family: Dynamic and growing. Structure 17:160-171. 